\title{
HyperCourseware for interactive instruction in the electronic classroom
}

\author{
KENT L. NORMAN \\ University of Maryland, College Park, Maryland
}

\begin{abstract}
An electronic classroom with computer workstations and multimedia offers tremendous potential for interactive instruction. To support such instruction, HyperCourseware was developed as an environment and authoring system that recreates on a computer network familiar objects of instruction, such as the syllabus, lecture notes, class rolls, seating charts, exams, and grade lists. In addition, it provides interactive and collaborative tools for group discussion, anonymous feedback, student polling, and shared collaborative workspaces. Applications in statistics and cognitive psychology are discussed along with the specific advantages due to hypermedia links, structure of course materials, integration of parts, and classroom interactivity. Student and faculty evaluations have supported the positive educational benefits of both the electronic classroom and HyperCourseware in general.
\end{abstract}

An electronic classroom is a special room outfitted with computer workstations for each student and for the instructor. The computers serve multiple functions. They may be used for taking notes, for taking exams, for participating in class discussion, for presenting lecture and textbook material, as scratch pads, and sometimes as computers. All of the computers in the classroom are networked and tied into a shared file server, which allows information to be exchanged between the students and the instructor. In addition, the electronic classroom has highresolution video projectors that serve as electronic blackboards for displaying what is on any of the computer monitors or for use in multimedia presentations.

\section{The Electronic Teaching Theater}

Figure 1 shows a schematic for an electronic classroom at the University of Maryland, called the $A T \& T$ Teaching Theater. The room contains 20 student workstations with recessed desks to allow a good line of sight. All of the computers are located in an adjacent room to reduce noise. The classroom has two $4 \times 6 \mathrm{ft}$ high-resolution rear projection screens in the front. Video switching provides a seamless transition of input from the instructor's monitor, a VCR, a videodisk player, a slide projector, and a video overhead projector. All switching and control of audio/visual equipment is through a touch screen at the instructor's desk. Finally, all of the signals to and from

\footnotetext{
Requests for reprints or additional information about HyperCourseware and its availability should be addressed to K. L. Norman, Department of Psychology, University of Maryland, College Park, MD 20742. The author wishes to thank the staff of the AT\&T Teaching Theater for their technical support. For information about the availability of a demonstration copy of HyperCourseware as well as licensing agreements. contact the author directly.
}

Note: The author has a direct financial interest in some of the software described in this paper.-Editor the student workstations are routed through a switch that allows the instructor to display what is on any student monitor on the instructor's monitor and, in turn, on the large displays. Furthermore, any selected screen (student or instructor) can be displayed on the student monitors. The instructor can also intercept the keyboard and mouse to take control of a student workstation.

The electronic classroom is not a glorified computer lab in which one learns about computers-it is much more. The technology of the classroom provides a unique potential for the interactive and collaborative learning of any subject. The challenge has been to support and enhance the traditional activities of instruction and learning: (1) course development, (2) lecture presentation, (3) class discussion and interaction, (4) evaluation and record keeping, and, most essential, (5) an environment for exploration, discovery, and group collaboration. The approach taken in this project has been to develop a graphical user interface that supports the traditional materials and processes of classroom instruction while adding enhanced features made possible by the networked multimedia environment.

\section{HyperCourseware}

The two major problems resulting from the introduction of computers in the classroom have been (1) the lack of integration and connectivity between the myriad of programs available, and (2) the absence of unifying metaphors to help structure the implementation. Norman (1990) proposed that the traditional objects of classroom instruction should be matched in the electronic classroom. Objects such as the course syllabus, the lecture notes, the class roll, and so on, should be instantiated in graphic form in the electronic classroom. Furthermore, the concept of hypermedia should be used to link the objects together and allow users to navigate from the syllabus, to lecture notes, to the textbook, and so on. This approach has been implemented in the form of HyperCourseware in the elec- 


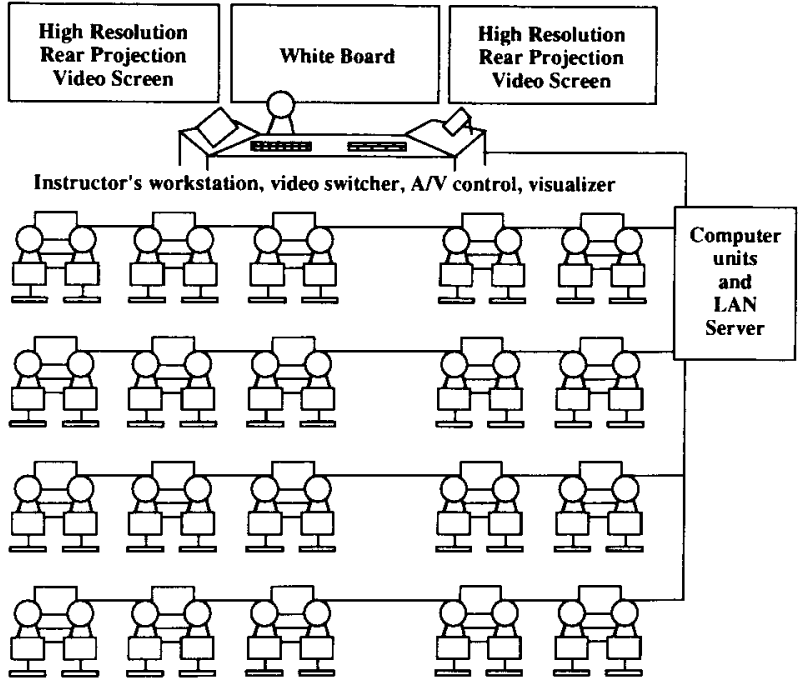

Twenty Student Workstations with Two Students Per Workstation

Figure 1. A schematic of the AT\&T Teaching Theater, showing two students at 20 workstations.

tronic classroom. HyperCourseware is a system of interlocking programs and files that serves as an electronic infrastructure for classroom and distance learning. It serves to create on a computer network what had previously been recorded in notebooks, on the blackboard, and in textbooks. HyperCourseware is currently in prototype form and implemented using Spinnaker Plus, a stackware application that runs in the Macintosh, Windows, or OS/2 operating systems.

As implemented in the AT\&T Teaching Theater, when a student signs onto a workstation with his or her account name and password, the system records the student's attendance and then presents the "home" screen shown in Figure 2. At this point, the student can add a partner to the left or right. The home screen displays daily announcements and serves as the central access to the HyperCourseware icons shown around the perimeter of the screen. Icons on the left represent course materials, icons on the right represent the products or output of the course, and icons at the bottom represent classroom tools.

Selecting any one of the icons opens up the corresponding HyperCourseware module. For example, the Syllabus icon opens up the syllabus. From the syllabus screen (Figure 3), students have access to all of the lecture notes for any particular day, the readings assigned that day, and the written assignments. The lecture notes screen shows an index of topics to be covered. Selecting one of the topics or paging forward accesses the graphic displays for the lecture. For example, Figure 4 shows material covered in statistics on frequency histograms. Many of these screens are interactive or use animation to illustrate a concept. For example, in a statistics course there are displays that show samples being drawn from a population, pictures of coins flipping to generate an observed binomial distribution, and equations that are filled in with data to show each step of the computations. In a course on cognitive psychology, screens are used to illustrate experiments in concept learning, choice reaction time, and short-term memory.

In a typical class, the students follow along from screen to screen in sync with the instructor. However, if they fall behind or get lost, they can select the Lecture icon from the home screen or a pointing tool on the navigational ribbon at the top of most screens. This tool finds the screen that the instructor is viewing and jumps directly to it.

The Readings and Assignments icons back on the home screen go directly to on-line readings and assignments or to instructions about them. The Assignments module in HyperCourseware lists the assignments and their due date. In most cases it provides a workspace for entering written material and submitting it to the instructor. The submission is copied to a file for the instructor to grade; it is then sent back to the student and the grade is recorded on the grade list.

Next, the Class Roll icon shows a list of all of the students. It also provides access to pictures and information about each student. Students enter their own autobiographical sketch, and the pictures are taken and entered by using a digitizing camera. The class roll provides a facility for the students and the instructor to get to know more about each other.

Classroom interaction tools are at the bottom of the home screen. The Directions icon provides context-dependent help on how to use the home screen. The Seating icon shows a class seating chart with the names of all the students at their locations. Figure 5 shows the seating chart from the instructor's perspective. Another seating chart, from the students' perspective, is available on their screens. Names in italics indicate students actually logged in on their accounts; other students are listed as partners at the same workstation. HyperCourseware records the location of each student when the student signs on and takes attendance. The Message icon accesses a simple electronic mail system between the students and the instructor. The instructor can send messages to any or all of the students and the students can send messages to the instructor.

The Discussion icon provides a number of facilities for an on-line form of discussion. For example, the instructor can post a topic or question to which the students write their comments. The collective comments appear for all the students to see. Another form of discussion is a continuous listing of all comments as they are submitted. The Feedback icon allows the student to enter questions to the instructor or to provide anonymous feedback about the course. The Exchange icon accesses a tool to swap files between students, to hand out files to students, and in general, to follow any model of file exchange among the students and the instructor. The World icon provides access to other programs outside of Spinnaker Plus (e.g., word processors, graphics packages, statistics programs) that 


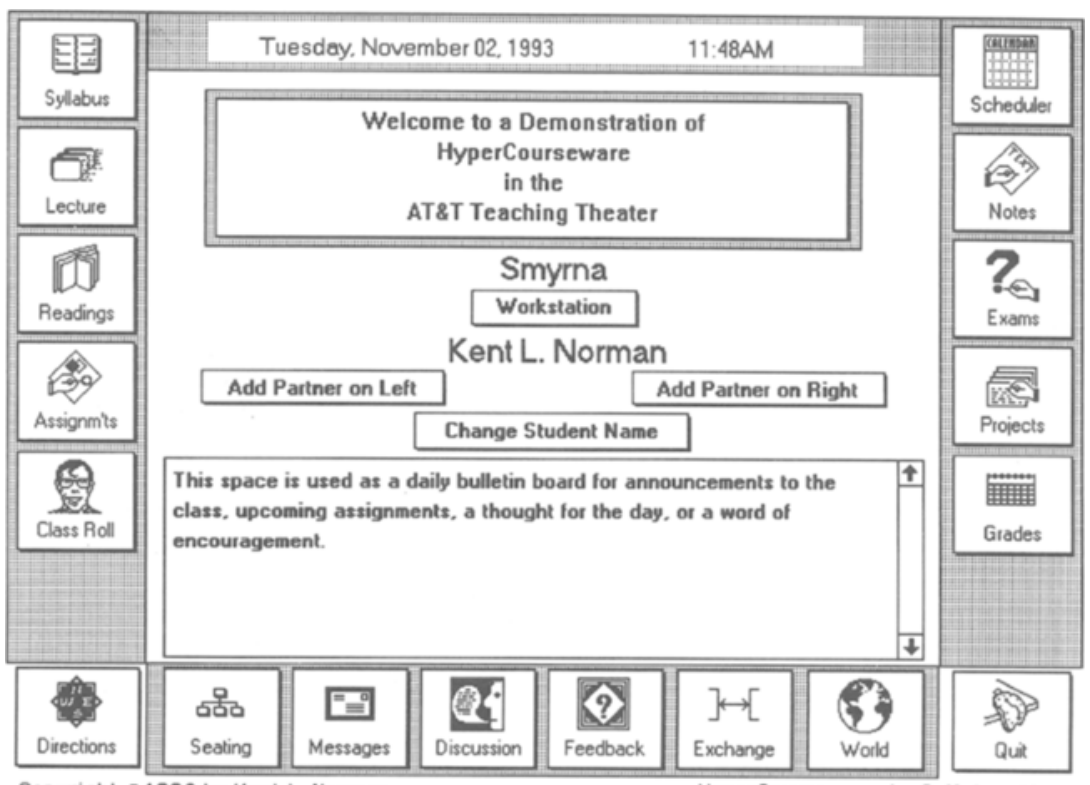

Copyright $\otimes 1992$ by Kent L. Normen

HyperCourseware by Collaboration

Figure 2. The "Home" screen in HyperCourseware, which acts as a navigational hub to access other modules.

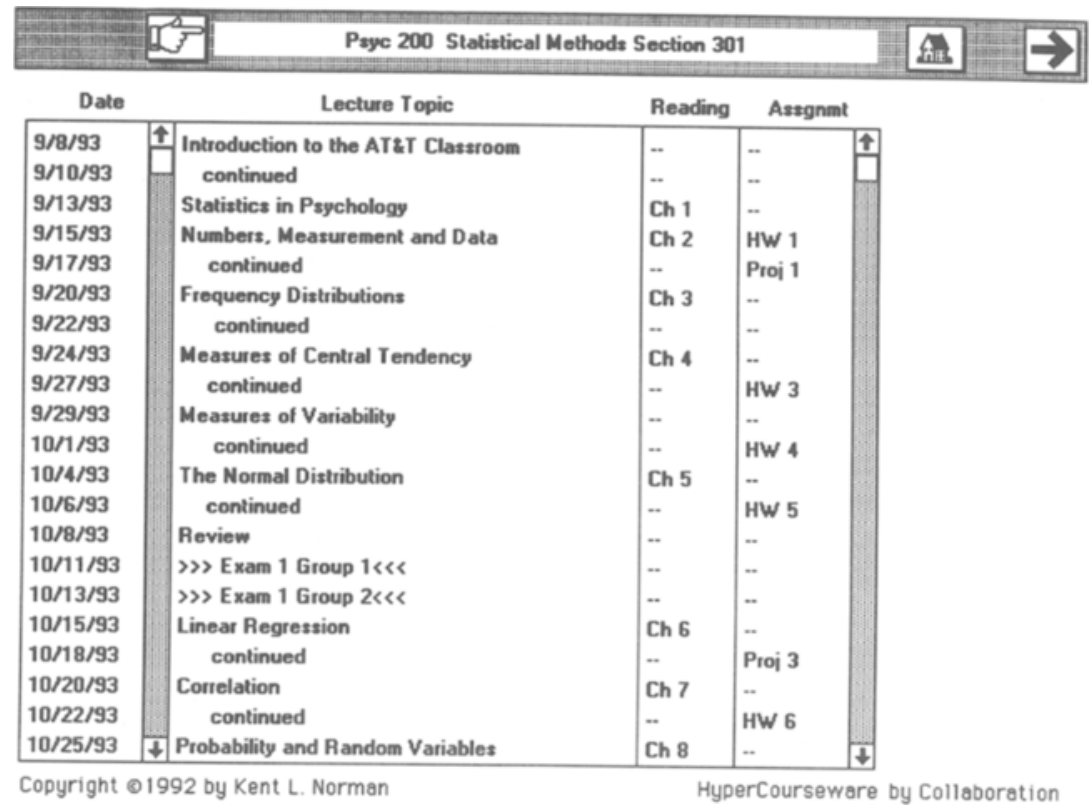

Figure 3. The syllabus module, which is used to organize materials and access lecture notes, readings, and assignments. 


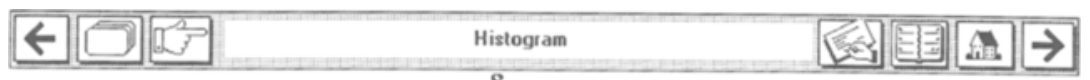

Uses bars to graph the frequency of each class interval.

\begin{tabular}{|llrr|}
\hline \multicolumn{4}{|l}{ Apparent Real } \\
Limits & Limits & Mdpt & f \\
\hline $98-100$ & $97.5-100.5$ & 99 & 3 \\
$95-97$ & $94.5-97.5$ & 96 & 4 \\
$92-94$ & $91.5-94.5$ & 93 & 8 \\
$89-91$ & $88.5-91.5$ & 90 & 1 \\
$86-88$ & $85.5-88.5$ & 87 & 4 \\
$83-85$ & $82.5-85.5$ & 82 & 4 \\
$80-82$ & $79.5-82.5$ & 81 & 1 \\
\hline & & & 25 \\
\hline
\end{tabular}

Bars extend from the lower to upper real limits of the intervals.

Copyright $\odot 1992$ by Kent L. Norman

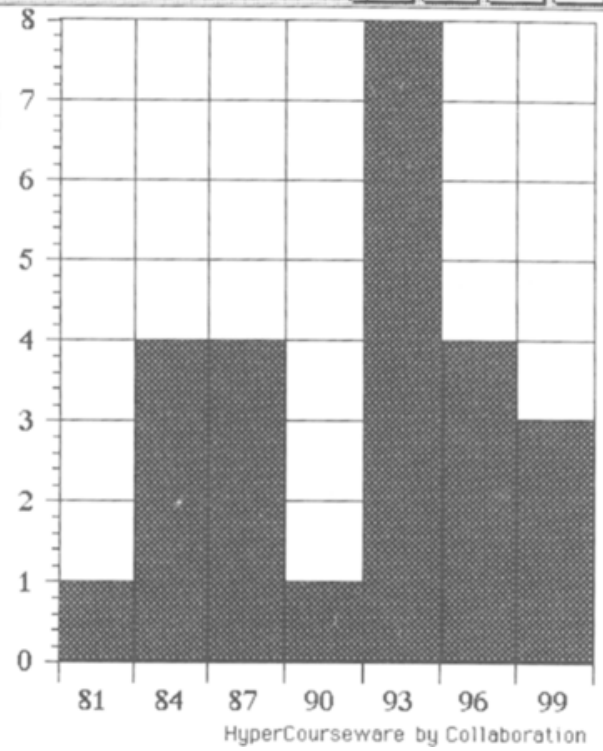

Figure 4. A lecture screen from a statistics course. The navigational ribbon at the top provides access to the previous screen, the index, the instructor's current screen, student notes, the syllabus, the home screen, and the next screen.
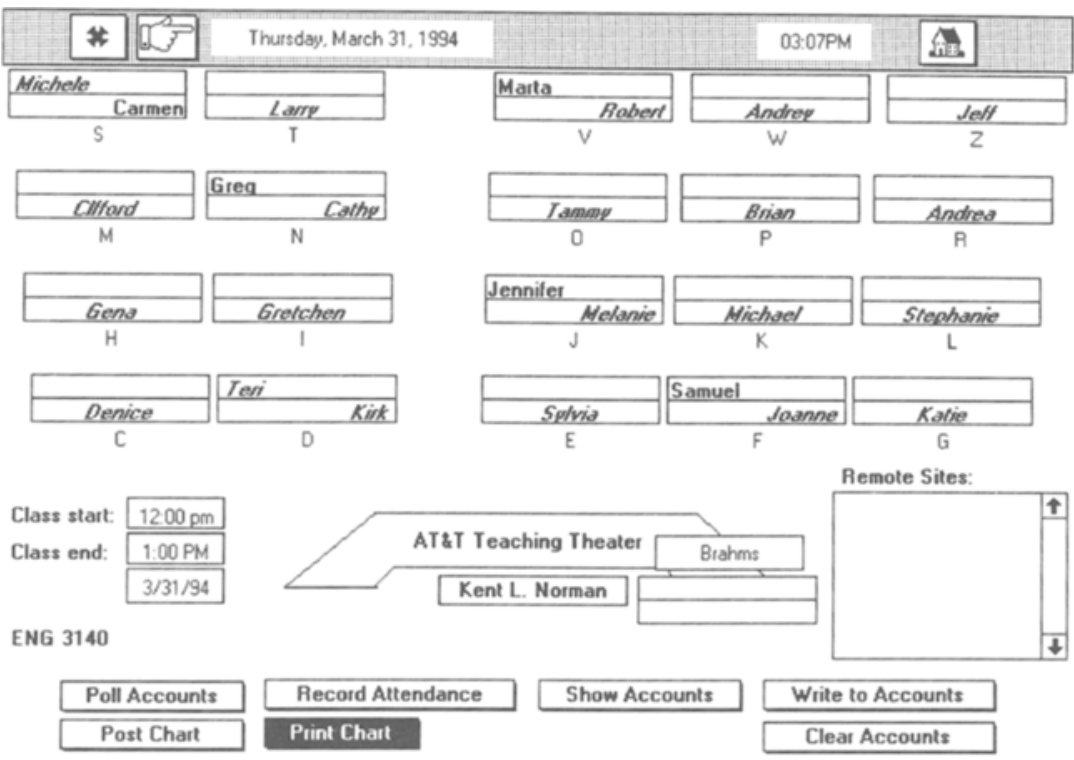

Copyright 1992 by Kent L. Norman

HyperCourseware by Collaboration

Figure 5. Class seating chart as seen from the instructor's perspective, showing the 20 workstations and names of students seated at each station. 
reside on the computer system. Finally, the Quit icon logs the student out of the system and records information about the session.

Along the right-hand side of the home screen are icons for the student-generated products of instruction. The Scheduler icon provides a tool for planning and recording one's study of material and completion of assignments. The Notes icon allows students to record and view their own notes, or notes taken as a group by the class. The Exams icon is used to start exams and quizzes when they were scheduled or to view them after they have been graded. The Projects icon provides a collaborative work space for group projects. For example, if two students are working on a project together, the Projects icon allows both students to access the same file. Finally, the Grades icon allows the students to see their current grades on exams and assignments.

\section{Positive Benefits}

HyperCourseware provides four features that are essential to both its ease of use and educational benefit: (1) hypermedia links, (2) structure of course materials, (3) integration of parts, and (4) classroom interactivity.

Hypermedia links provide meaningful associations from one point to another. Links may be linear, corresponding to a logical sequence of steps (e.g., the steps to conduct a statistical test); they may be tangential, providing access to ancillary information (e.g., examples, details, definitions); or they may be nonlinear references that form a web of associations. Navigation through the material is a function of the hypermedia links embedded in the material as well as of generic navigational functions for accessing modules, paging through the materials, and returning to indexes and navigational hubs.

The structure of the course materials within HyperCourseware provides order both between and within HyperCourseware modules. For example, the syllabus provides the overall structure to the course materials, and within a lecture module each index provides an order to the screens. Rather than dealing with many unordered pieces of information, the course structure allows the students to descend from the syllabus into the lecture topics and from the lecture topics into the lecture details. Within a lecture stack the instructor imposes a structure, generally a linear path, through the materials. Readings, assignments, and exams are ordered and linked in a similar way.

HyperCourseware integrates all aspects of classroom education together in a seamless package. Rather than jumping from one application to another or from one window to another, and rather than cutting and pasting information, HyperCourseware links lecture materials, readings, students' notes, class rolls, exams, grades, and so on. This enables students and instructors to navigate through all of the materials from one part to another and also enables information generated in one part (e.g., grade on an exam) to be used in another (e.g., computation of final grade).

Finally, HyperCourseware exploits the interactive nature of hypermedia and the collaborative support of networks. Simulations and animation are used to illustrate models and processes such as binomial sampling distributions in statistics and feedback models in cognitive psychology. In classroom discussions, ideas or comments generated simultaneously by individual students can be collected, aggregated, and disseminated to the class. Students working on projects as a team access common modules and contribute different parts to the final product.

\section{Evaluation}

A number of classes from diverse disciplines have been taught in the AT\&T Teaching Theater. Both informal and formal evaluations have been conducted, providing evidence of ease of use, student satisfaction with the system, and the positive educational benefits of the room (Norman, 1992). HyperCourseware has been used to support three classes in psychology: introduction to statistics, thinking and problem solving, and a seminar in cognitive psychology. In each case, materials were authored and presented in HyperCourseware. During the class sessions students had individual access to explore the materials and to use the interactive and collaborative tools. Student evaluations of HyperCourseware have been quite positive relative to the traditional classroom, despite a number of software and hardware problems (Norman \& Lindwarm, 1993). Moreover, students have suggested a number of improvements, such as to (1) increase out-of-class access to the materials, (2) increase ease of use, (3) provide additional templates for the development of course materials, (4) provide additional interactive capabilities, and (5) explore distal collaborative teaching with other universities. Such changes and enhancements are ongoing in the development of HyperCourseware.

\section{REFERENCES}

Norman, K. L. (1990). The electronic teaching theater: Interactive hypermedia and mental models of the classroom. Current Psychology Research \& Reviews, 9, 141-161.

NoRMAN, K. L. (1992). Defining and assessing usability in emerging systems: A case study of the electronic classroom. Proceedings of Usability Concepts and Procedures: Third Conference on Quality in Documentation (pp. 83-95). University of Waterloo, Centre for Professional Writing.

NoRMan, K. L., LINDWARM, D. (1993). Human/computer interaction in the electronic classroom. In Proceedings of the Mid-Atlantic Human Factors Conference (pp. 217-223). Virginia Beach, VA. 